\title{
Making a Successful Case for a Hypertextual Doctoral Dissertation
}

\author{
Christine Boese \\ Department of English \\ Clemson University \\ Clemson, SC USA 29634 \\ Tel: 864-656-5416 \\ E-mail: cboese@clemson.edu
}

\begin{abstract}
In August, 1998 the first hypertextual dissertation at Rensselaer Polytechnic Institute was accepted (http://www.nutball.com), a case study applying methods of rhetorical analysis and cultural critique to the online phenomenon called the "Xenaverse," the cyberspaces devoted to the cult following of the syndicated television program Xena, Warrior Princess. The hypertextual research site, a vital online culture, seemed to demand a new kind of scholarship to describe and analyze it. Still, there were many hurdles to getting such an unorthodox presentation form accepted by the dissertation committee and the Graduate School.
\end{abstract}

This paper summarizes a few of the justifying arguments that led to the successful acceptance this dissertation, a hypertext that could not be reproduced in any way on paper. In showing how one case for a hypertextual dissertation was successfully argued, I hope to help other scholars make similar cases at other institutions, perhaps leading to further debate on the ways arguments and epistemologies will be defined in the future.

KEYWORDS: hypertext dissertation electronic scholarship online cultural studies library archives University Microfilms graduate school Xenaverse Xena

\section{INTRODUCTION}

There are good and bad reasons for wanting to attempt a hypertextual dissertation. An attempt at hypertextual scholarship should not be motivated by a gratuitous desire to find any excuse to hypertextualize an argument. David Kolb, in a number of his works [1][2] has raised important reservations about hypertextual forms of academic arguments, especially because linearity and coherence have often been seen as essential features of good arguments. Some argue that dissertations are by definition linear, and therefore something that is nonlinear cannot actually be a dissertation. I agree that dissertations must present an argument, but I remain unconvinced that arguments are essentially defined by their linearity. The field of rhetoric in particular shows us how most arguments that strive for linearity are not fully linear, and are instead dependent on enthymemes and other rhetorical figures and stances.

Meanwhile, some of us are in search of truths that don't proceed linearly, that build a persuasive case by accumulation and reiteration, by inviting users to make their own connections and to actively construct truths from extensive archives and linked appendices.

However, the best reason for attempting a hypertextual dissertation is that the content of the research demands it. In the case of the cyberspace-based virtual world called the "Xenaverse," an ethnographic study could take into account the hypertextual virtual culture created, describe it on its own terms, and then circle back and analyze the findings. The dissertation could contain both detailed description and critical rhetorical analysis, cross-linked and tied directly to the sites of the study's co-participants. With this in mind I began the project, The Ballad of the Internet Nutball: Chaining Rhetorical Visions from the Margins of the Margins to the Mainstream in the Xenaverse (http://www.nutball.com).

\section{WHAT FORM SHOULD IT TAKE?}

How do I effectively report back on my research? How much hypertextual knowledge and understanding would be lost in the translation from webbed text to linear print text? The data consist of multiple media strung across a web of links. The shape of the dissertation content, both my own description and analysis and the many voices of the people who live in my data, is primarily non-hierarchical, decentering, marginal, polyvocal, multi-threaded, in short, hypertextual. My goal was to move outside of the standard, linear, centered form for a dissertation argument in order to devise an alternative, perhaps more expansive, form for my persuasion in hypertext. The hypertextual performance of this dissertation was merely one step toward testing whether nonlinear arguments can be made in hypertext, a challenge put forth by David Kolb in "Socrates in the Labyrinth" [1] and "Discourse Across Links" [2].

If closure doesn't always happen down a predetermined 
route, how do I judge, how does my dissertation committee judge, whether I have successfully completed and defended a dissertation that exists in native hypertextual, multimedia form? Perhaps what I am making is more of a hypertextual creative work of considerable substance, a performance, a representation of a dissertation in experimental form. However, this does not mean that my argument cannot be effective and persuasive, and thus still meet the institutional requirements for dissertations.

This project sought to link and merge with the webbed Xenaverse culture in cyberspace. To learn about the Xenaverse, the power relationships and constructions of authority within it, the user is invited to step through a scholarly portal, to become immersed, explore, both within and beyond the blurred boundaries of the dissertation and into the Xenaverse itself. I made a choice to match the form of my dissertation to the webbed environment of the Xenaverse, in order not to lose the hypertextual knowledge and understanding that could perhaps be gained from associational linking and dialogic interactions between frames and windows.

\section{INSTITUTIONAL CONSTRAINTS}

With a dissertation I couldn't be as free form as I might have been in a fictional piece. If I had been more experimental, I would have run the risk that the dissertation would have been unacceptable to the Graduate School. My committee was receptive to experimentation, and eventually voiced concern that I had been too conservative in structuring the interface. However, I had to find a way to ensure that the major argumentative points of my study were communicated through multiple paths and navigational styles. I attempted to do that by building redundancies into the content for a holistic effect. I also attempted to build recursiveness into the link structure, so that patterns of links would lead the reader back around and around until unexplored sectors will almost inevitably be reached.

There were also some key negotiations made between the chair of my doctoral committee, the Graduate School, and myself. Our research indicated that University Microfilms had been accepting CD-ROM dissertations since 1996, and it was heralded as a sign of progress in the "Information Technology" section of The Chronicle of Higher Education [3].

Upon contacting University Microfilms in 1998, however, I was told that the electronic submission policy only applied to Portable Document Format (.pdf) files, in other words, facsimile document files that faithfully reproduced images of a paper dissertation. The person I spoke with had no idea what University Microfilms would do with the multimedia dissertations written about in the Chronicle article. These were described as traditional linear dissertations with extensive support media (e.g. video clips, photographs). There was no mention of what would be done with the nonlinear structuring of hypertextual forms. Eventually I came upon the same difficulty with the Rensselaer Polytechnic library: lack of a digital archive.
I had developed an interface of dialogically interacting frames and windows forming a composite text. In the first round of negotiations over a "no paper" dissertation with the Graduate School, I was asked if I could just print out all the Mainscreens, negating the effects of nonlinear linking. My advisor, David Porush, and I had decided early on that if an electronic dissertation could be reproduced on paper, then there was really no compelling reason for it to be in electronic form at all.

To its credit, the Rensselaer Graduate School was remarkably open-minded. I proposed a small introductory text that would contain instructions on how to install the CD-ROM or access the Web site. This small amount of paper could be hardcover bound, with an envelope affixed to the inside back cover for the CD-ROM. Finally a compromise was reached. The Graduate School required that each dissertation have four sections, an Abstract, an Introduction, a Conclusion, and a Bibliography. In the end, the paper component totaled 73 pages.

The greatest obstacle to the archival longevity of the project had to do with the Institute's lack of stable, long-term digital storage and access space on the Internet. I needed a permanent Uniform Resource Location (URL) that I could publish in the paper archives. I had to take it upon myself to provide a stable and permanent URL for the site, paying to register a DNS as well as the monthly server space rental.

\section{CONCLUSION}

I hope that other scholars can add to the development of such cases like this, opening the door for a more firmly established genre of hypertextual scholarship. We also must consider the traditional and not-so-traditional institutional constraints for archiving and referencing such work, and advocate changing the storage system assumptions made by University Microfilms and library archives in making hypertextual electronic scholarship available to other researchers. Electronic dissertations that are exact representations of paged paper texts show little justifying reason for being created and stored in digital form, other than the expedience of saving library shelf space. Some scholars are using digital materials to archive multimedia rich data appendices, but the form of their argument remains primarily conventional. There is much more work to be done.

\section{REFERENCES}

1. Kolb, D., Socrates in the Labyrinth, in Hyper/Text/Theory, G.P. Landow, Editor. 1994, Johns Hopkins University Press: Baltimore, MD.

2. Kolb, D., Discourse across Links, in Philosophical Perspectives on Computer-Mediated Communication, C. Ess, Editor. 1996, State University of New York Press: Albany, NY.p. 15-26.

3. Mangan, K.S., CD-ROM Dissertations: Universities consider whether new format is appropriate way to present research. The Chronicle of Higher Education, 1996(March 8, 1996): p. A15-A19. 